Article

\title{
Theoretical Study of the Effects of Spark Timing on the Performance and Emissions of a Light-Duty Spark Ignited Engine Running under Either Gasoline or Ethanol or Butanol Fuel Operating Modes
}

\author{
Roussos G. Papagiannakis ${ }^{1}$, Dimitrios C. Rakopoulos ${ }^{2}$ and Constantine D. Rakopoulos ${ }^{2, *}$ \\ 1 Thermodynamic \& Propulsion Systems Section, Aeronautical Sciences Department, \\ Hellenic Air Force Academy, Dekelia Air Force Base, 1010 Dekelia, Attiki, Greece; \\ r.papagiannakis@gmail.com \\ 2 Internal Combustion Engines Laboratory, Department of Thermal Engineering, \\ School of Mechanical Engineering, National Technical University of Athens, Zografou Campus, \\ 9 Heroon Polytechniou Street, 15780 Athens, Greece; dimracop@central.ntua.gr \\ * Correspondence: cdrakops@central.ntua.gr; Tel.: +30-210-772-3529
}

Received: 26 May 2017; Accepted: 9 August 2017; Published: 13 August 2017

\begin{abstract}
Much research is ongoing to find suitable alternate fuels in order to reduce the exhaust emission levels without deteriorating the basic performance characteristics of conventional spark-ignited (SI) engines. One of the methods to achieve the above problem is the use of alcohols as full supplement fuels to normal gasoline. At the same time, many related research studies have shown that the use of alcohols has a negative impact on some basic engine performance characteristics, e.g., brake power output, etc. On the other hand, spark timing is one of the critical engine operating parameters that significantly influences the combustion mechanism inside the combustion chamber of a SI engine. Therefore, the primary objective of the present work is to investigate the effect of spark timing on the performance and emissions characteristics of a conventional, four-stroke, SI engine running under three different fuel operating modes, viz. with conventional gasoline or ethanol or butanol. The specific investigation is conducted by using an in-house, comprehensive, two-zone phenomenological model. The predictive ability of the model is tested against pertinent experimental data and it is found that the computed results are in good agreement with the respective experimental ones. For all test cases examined herein, the results concern basic engine performance characteristics, i.e., cylinder pressure, power output, specific fuel consumption etc., as well as $\mathrm{NO}$ and $\mathrm{CO}$ emissions. The main objectives of the work were to record and evaluate the impact that spark timing has on the performance characteristics and emitted pollutants of a conventional SI engine, operating under either conventional gasoline or ethanol or butanol fuel operating modes. Moreover, it deals with the determination of an optimum combination between the type of fuel used and the spark timing, so that probable undesirable effects on engine performance characteristics would be avoided. By comparing this investigation results, it is revealed that the use of alcohols as a full substitute fuel of gasoline accompanied with an appropriate alteration of the spark timing, could be a promising solution to improving both the efficiency and environmental behavior of a light-duty, spark-ignited (SI) engine, without causing any harmful problems to the engine operational lifetime. The conclusions from the study may prove valuable for the application of this technological solution to existing conventional SI engines.
\end{abstract}

Keywords: SI engine; two-zone model; ethanol; butanol; spark timing; performance; emissions 


\section{Introduction}

The large increase in air pollution observed in recent decades is one of the most important problems in developed countries. Exhaust emissions emitted by piston internal combustion engines play a very important role in this problem. The legal regulations that control this problem set ever closer limits on the emission levels of motor vehicles. Therefore, in addition to changing the engine design, it is now necessary to find technologies that will allow the use of alternative fuels (i.e., biofuels) in new or existing piston internal combustion engines. Despite the fact that fuel prices are today at historical lows and, furthermore, the degree of sustainability of the production of biofuels is a matter of great discussion, it is very important and beneficial that the alternative fuel used has to be produced from renewable energy resources and, moreover, it must be immediately usable. In addition, the use of alternative fuel in existing engines without requiring significant changes to the engine structure should be possible [1-4]. Thus, the rising fuel prices and the increased oil consumption along with the lack of sustainability of oil-based fuels have generated vivid interest in alternative, renewable sources of fuels for motor vehicles. Bio-fuels made from agricultural products (oxygenated by nature) can reduce the world's dependence on fossil fuels imports, support local agricultural industries and, what is more, offer benefits in terms of usually reduced exhaust emissions. Among those, alcohol-based fuels are considered as very promising fuels, which could possibly replace fully the conventional liquid fuel (gasoline or diesel fuel) in reciprocating internal combustion engines [5-7].

The influence of an alcohol-based fuel on the performance and emissions of an internal combustion engine has been widely investigated. Specifically, many of the theoretical and experimental studies evaluating the potential of alcohols are based on ethanol [8-16], while other studies have been performed on butanol-fueled engines [17-21], or on assessing $n$-butanol as a blending agent with gasoline [22-26]. Ethanol can be used as a neat fuel in spark-ignited engines or blended up to $40 \%$ with diesel fuel for use in compression-ignition (CI) engines [8-16]. Ethanol is biodegradable, it is less detrimental to ground water, and it has an octane number higher than gasoline with positive effect on vehicle emissions [14-16]. While ethanol is soluble in gasoline, additives are required to ensure its solubility in diesel fuel, especially at lower ambient temperatures, and moreover its addition to diesel fuel can reduce lubricity leading to wear problems in fuel pumps [14-16]. While ethanol seems to be the most usual alcohol for automotive applications, butanol seems to be also promising as its properties are closer to gasoline than those of ethanol. Butanol is a viable alternative to ethanol and offers several benefits over ethanol, while it can be produced also from the fermentation of sugars in biomass $[6,7,17]$. Butanol is less corrosive than ethanol and is less prone to water contamination, hence allowing it to be transported using existing fuel supply pipelines. Moreover, butanol has a higher lower heating value as compared to the respective value of ethanol, which is much closer to the lower heating value of gasoline $[6,7,17]$. This fact, combined with the higher stoichiometric air-fuel ratio, permit higher blending levels of butanol in gasoline than ethanol without changing regulations and engine control systems. Additionally, butanol has a lower latent heat of vaporization than ethanol, which could reduce issues related to fuel atomization and combustion during cold start conditions $[6,7,17]$. Butanol also offers benefits over ethanol for use in $\mathrm{CI}$ engines including a higher cetane number, lower vapor pressure, and improved miscibility in diesel fuel [6,7].

Several studies have already been performed in order to investigate the use of both types of alcohols in spark-ignited engines, either blended with gasoline [8-21] or as a neat fuel [22-26]. A review of ethanol/gasoline blends impact on performance and emissions of a spark-ignited engine is given in [8-16]. In [17-26] results are given concerning the use of butanol, either blended with gasoline or as a neat fuel, in a spark-ignited engine. By observing these results, it can generally be concluded that the increase in alcohol content in the blend with gasoline, could have a significant impact on engine performance and efficiency only at high alcohol concentrations, if the air-fuel ratio is to be maintained within the same range of values as for the gasoline operation.

Despite the aforementioned appeared literature concerning the use of both types of alcohols (ethanol or butanol) in a conventional spark-ignited engine, there is still room for further knowledge 
on how the slight change in spark timing would affect the performance characteristics and the pollutant emission levels of an existing, light-duty gasoline engine that could operate by using biofuels (neat-ethanol or neat-butanol) instead of gasoline.

Therefore, the primary objective of the present work is to examine, on a theoretical basis (i.e., by using of a two-zone phenomenological model), the effect of spark timing on the performance and emission characteristics of an existing, light-duty, naturally aspirated, spark-ignited engine operating at two different engine loading conditions, by using biofuels (neat-ethanol or neat-butanol) instead of gasoline [5,27-29]. In this study an existing two-zone phenomenological combustion model was used, which simulates the closed part of the operating cycle (closed cycle) of a conventional, 4-stroke, SI engine. The basic philosophy of the model has not been modified at all. However, in order to allow the model to be used in the present study, some modifications have been made, which have to do with the estimation of some critical parameters, such as the cylinder charge conditions at Inlet Valve Closure event, the air and fuel mass flow rates, and the laminar flame velocity. The theoretical results obtained from the application of the above simulation model consist of the in-cylinder gas pressure, the in-cylinder rate of heat release history, the duration of combustion, the indicated specific fuel consumption as well as the specific NO and CO emissions. Before the application of the proposed model, its predictive ability was evaluated by using experimental data obtained from [14]. More specifically, model predictions corresponding to engine operation at $2400 \mathrm{rpm}$ speed and normal spark timing, i.e., NSA = 23 degrees crank angle before top dead center (deg CA BTDC), are validated against the corresponding experimental values obtained from a single-cylinder, naturally aspirated, air-cooled, spark-ignited engine, which operates either under the G100 or the E100 operating modes at full engine loading conditions [14]. All the theoretical results are referred to engine operation at various combinations of engine loads and spark timings, for each one of the three different fuel operating modes, viz. gasoline operating mode: G100, butanol operating mode: B100, and ethanol operating mode: E100.

By comparing both the computational and the experimental findings, it is observed that for the two different fuel operating modes examined herein, the simulation model accurately predicts the variation trends in engine performance characteristics and pollutant emissions. Taking into account the fact that the conclusions of the present study are based on the comparative assessment of the simulation results, which attempt to describe the relative impact of the two parameters (fuel type and spark timing) on performance characteristics and pollutant emissions of an existing, four-stroke, spark-ignited engine, it becomes obvious that the proposed model could safely support the main purpose of this study.

This work reveals important information about the impact of spark timing in combination with the type of biofuel (ethanol or butanol) on performance characteristics and specific $\mathrm{NO}$ and $\mathrm{CO}$ emissions, of an existing light-duty, spark-ignited, gasoline engine. Consequently, the information derived from the present work is extremely valuable regarding the implementation of spark timing alteration for improving the engine efficiency and environmental behavior for an existing spark-ignited engine, when the conventional gasoline fuel will be fully substituted either by butanol or by ethanol, without detrimental repercussions on the constructional endurance of the engine. To the authors' best knowledge no such study has been reported before.

\section{Brief Description of the Simulation Model}

\subsection{Main Philosophy of the Model}

The proposed model is a relatively simplified phenomenological two-zone combustion approach, simulating the "closed part" of the operating cycle of a conventional, 4-stroke, spark-ignited engine. More details about the structure of the model as well as data and results concerning the application of the model on various types of spark-ignited engines have been published by the authors in the 
past $[5,27-29]$. Therefore, in the specific sub-paragraph it will be given only a general description of the basic philosophy of the model.

After the inlet valve closing (IVC) event and during the compression stroke up to the initiation of combustion, the charge of the cylinder is considered as a uniform air-fuel mixture, i.e., a fuel vapor and air vapor mixture, which has been premixed during the intake stroke. During the compression phase, the estimation of the in-cylinder gas pressure and temperature is carried out by using an one-zone phenomenological model, while the perfect gas law describes the state of the mixture inside the cylinder [5,27-29]. The combustion process is treated as a two-stage procedure comprised of the ignition process and the stable flame propagation process [5,27-29]. The ignition process consists of the formulation of the flame kernel due to spark electric discharge and its unsteady flame propagation. After the initiation of combustion, a two-zone phenomenological model is considered to be present for the rest of the closed part of the engine cycle. The first zone consists of air-gaseous fuel mixture (unburned zone), while the second one (burning zone) consists of the combustion products. The two zones are separated by a flame front, which has spherical shape and spreads into the cylinder towards the unburned zone. According to the basic design philosophy of the proposed model, there is no heat exchange between the zones and, furthermore, the flame front is treated as negligibly thin [30-36].

During the combustion process, the flame front spreads towards the unburned zone with a flame speed that is calculated by taking into account the turbulent flame propagation mechanism [30-36]. The computation of the instantaneous flame geometry is achieved by applying the model developed by Annand [36]. The masses of both the fuel and the air entraining into the burning zone are determined by using the volume change rate of the spreading spherical flame front. According to the basic design philosophy of the proposed model, the gaseous fuel entrained inside the burning zone is transformed immediately into products. Therefore, it is revealed that both the turbulent flame speed and the basic characteristics of the mixture (pressure, temperature, and composition) are the only parameters affecting considerably the combustion rate and hence, the heat release rate. It must be stated here that the expansion velocity of the spherical burned flame front is taken into account for the estimation of the final flame speed [5,27-29]. Because engine-knocking is a phenomenon that often occurs in SI engines, it should be taken into account in any theoretical study of the performance of a spark-ignited engine. In the present model, a rather simplified but efficient approach to model knock in SI engines has been adopted. According to this approach, the auto-ignition of the unburned mixture occurs when the time integral of the inverse of the induction time becomes equal to unity. The induction time is modeled by an Arrhenius type equation, which relates that to the cylinder pressure and temperature of the unburned zone [30-36].

According to the proposed model, the heat exchange rate between the cylinder charge and the cylinder walls is estimated through the application of the well-known Annand approach [37]. During the application of the two-zone approach, a bulk average temperature of both zones is estimated and afterwards the total heat exchange rate is distributed between the two zones according to their mass, temperature, and specific heat capacity [5,27-29].

After the initiation of combustion each zone possesses its own temperature and composition, while the pressure is uniform inside the cylinder. According to references [30-32,38,39], chemical equilibrium condition for the combustion products is considered to prevail during the whole phase of the expansion stroke up to the exhaust valve opening event. The chemical equilibrium species considered are $\mathrm{H}_{2} \mathrm{O}, \mathrm{H}_{2}, \mathrm{OH}, \mathrm{H}, \mathrm{N}_{2}, \mathrm{NO}, \mathrm{N}, \mathrm{CO}_{2}, \mathrm{CO}, \mathrm{O}_{2}$ and $\mathrm{O}$, while the molar concentration of each one of the aforementioned 11 species is calculated by employing the well-known approach proposed by Vickland et al. [38,39]. The extended Zeldovich mechanism with minor modifications has been adopted for the estimation of NO formation. Finally, according to model's basic philosophy, both the formation and the oxidation mechanism of the carbon monoxide (CO) are modeled in a similar way as the respective ones for $\mathrm{NO}$, by using the kinetics of the main formation and oxidation reactions, by combining carbon monoxide, carbon dioxide $\left(\mathrm{CO}_{2}\right)$ and hydroxyl radical $(\mathrm{OH})[30-32,38,39]$. 


\subsection{Estimation of Cylinder Charge Conditions at Inlet Valve Closure Event}

As mentioned, the present model simulates the part of engine cycle corresponding to the time interval where both inlet and exhaust valves are closed (closed cycle) for a conventional, natural aspirated, spark-ignited engine, in which the preparation of the air-fuel mixture takes place in the intake manifold during the induction stroke. Moreover, the simulation model assumes that the cylinder charge can be considered as a homogeneous mixture of air and gaseous fuel, which has been properly premixed during the induction stroke. Since the cylinder charge conditions (pressure and temperature) corresponding to inlet valve closure event $\left(P_{\mathrm{IVC}}, T_{\mathrm{IVC}}\right)$ are used by the present model as input values, in this subsection a brief description is given of the methodology followed for the estimation of these parameters.

Initially, it must be stated here that for the specific type of engine, the load adjustment is quantitative and it is controlled by throttling of the inducted mass flow rate of the air-fuel mixture. This means that a change in the engine loading conditions should be accompanied by a change in the mass flows of both the inlet air and the fuel consumed, so that the fuel equivalence ratio of the cylinder charge remains substantially constant. Thus, if $(\mathrm{a} \%)$ represents the percentage of full load, being equal to the percentage of the throttling of the inducted mixture, then the cylinder charge pressure corresponding to inlet valve closure event $\left(P_{\mathrm{IVC}, \mathrm{a} \%}\right)$ can be estimated through the formula:

$$
P_{(\mathrm{IVC}, \mathrm{a} \%)}=(\mathrm{a} \% / 100) \times P_{\mathrm{a}}
$$

where $\left(P_{\mathrm{a}}\right)$ is the ambient pressure and $(\mathrm{a} \%)$ represents the percentage of full engine loading conditions (i.e., full load: $a=100 \%$ ). Taking into account the fact that the engine tested herein is a naturally aspirated one and also that the throttling of the inducted mixture is assumed as an isenthalpic process of an ideal gas, the engine volumetric efficiency could be estimated by the formula:

$$
\eta_{\mathrm{v}} \cong\left(T_{\mathrm{a}} / T_{\mathrm{IVC}}\right)
$$

where $\left(T_{a}\right)$ represents the ambient temperature and $\left(T_{\text {IVC }}\right)$ corresponds to cylinder charge temperature at inlet valve closure event, which is affected by the heat of vaporization of the fuel used ( $\left.h_{\text {fuel,vap }}\right)$. As known, the use of a fuel with increased heat of vaporization leads to lower values of the cylinder charge temperature at inlet valve closure event, hence resulting to higher engine volumetric efficiency. Thus, for the specific type of engine, by correlating the available experimental volumetric efficiencies recorded for various types of fuels used in the present contribution $[14,16,17]$, the engine volumetric efficiency $\left(\eta_{\mathrm{v}}\right)$ as a function of the fuel heat of vaporization $\left(h_{\text {fuel,vap }}\right)$ could be estimated through the following formula:

$$
\eta_{\mathrm{v}}=70.56+8.23 \times 10^{-3} \times h_{\text {fuel,vap }}+2.64 \times 10^{-6} \times\left(h_{\text {fuel, }, \text { vap }}\right)^{2}
$$

Finally, by combining Equations (2) and (3), the temperature of the cylinder charge prevailing at inlet valve closure event could be estimated as:

$$
T_{\text {IVC }}=T_{\mathrm{a}} /\left(70.56+8.23 \times 10^{-3} \times h_{\text {fuel,vap }}+2.64 \times 10^{-6} \times\left(h_{\text {fuel,vap }}\right)^{2}\right)
$$

\subsection{Estimation of Air and Fuel Mass Flow Rates}

According to the previous sub-section, for the specific type of engine operating at specific loading conditions under constant engine speed, the mass flow rate of fuel consumption could be estimated through the following formula:

$$
\left(m^{\prime}\right)_{\text {fuel }, \mathrm{a} \%}=(\mathrm{a} \% / 100) \times\left(P_{a} / R / T_{\text {IVC }}\right) \times\left(V^{\prime}\right)_{\mathrm{h}} \times\left(\phi /\left\{\mathrm{AFR}_{\mathrm{st}}+\phi\right\}\right)
$$


where $(\mathrm{a} \%)$ represents the percentage of full engine loading conditions, $\left(V^{\prime}\right)_{\mathrm{h}}$ is the engine swept volume flow rate, $(\phi)$ is the fuel equivalence ratio of the cylinder charge, $\left(\mathrm{AFR}_{\mathrm{st}}\right)$ represents the stoichiometric air to fuel ratio, and $(R)$ is the gas constant for the gaseous air-fuel mixture.

It must be stated here that each one of the alcohol-based fuels used in the present investigation (i.e., butanol and ethanol) consists of carbon $(\mathrm{C})$, hydrogen $(\mathrm{H})$ and oxygen $(\mathrm{O})$ atoms. Some of the physical and chemical properties of these types of fuels are given in Table $1[14,16,17]$. Thus, the stoichiometric air to fuel ratio $\left(\mathrm{AFR}_{\mathrm{st}}\right)$ and the net calorific value for each one of the fuels used herein are calculated by knowing the chemical composition of the fuels.

Table 1. Basic physical and chemical properties of the test fuels used in the present work.

\begin{tabular}{lcccc}
\hline \multicolumn{1}{c}{ Property } & Unit & Gasoline & n-Butanol & Ethanol \\
\hline Chemical formula & - & $\mathrm{C}_{5} \mathrm{H}_{12}$ & $\mathrm{C}_{4} \mathrm{H}_{9} \mathrm{OH}$ & $\mathrm{C}_{2} \mathrm{H}_{5} \mathrm{OH}$ \\
Composition $(\mathrm{C}, \mathrm{H}, \mathrm{O})$ & $\% \mathrm{~m} / \mathrm{m}$ & $85,14,0$ & $65,14,22$ & $52,13,35$ \\
Lower heating value & $\mathrm{MJ} / \mathrm{kg}$ & 44.3 & 33.1 & 26.9 \\
Latent heat of vaporization & $\mathrm{kJ} / \mathrm{kg}$ & 349 & 585 & 923 \\
Stoichiometric air-fuel ratio & $\mathrm{kg} / \mathrm{kg}$ & 14.6 & 11.2 & 9.2 \\
Stoichiometric flame speed @ 1 bar \& 390 K & $\mathrm{cm} / \mathrm{s}$ & 34 & 39 & 45 \\
Density @ 20 ${ }^{\circ} \mathrm{C}$ & $\mathrm{kg} / \mathrm{m}^{3}$ & 745 & 810 & 790 \\
\hline
\end{tabular}

Finally, the actual mass flow rate of the inducted air in the cylinder corresponding to inlet valve closure event is calculated as:

$$
\left(m^{\prime}\right)_{\mathrm{air}, \mathrm{a} \%}=\left(\mathrm{AFR}_{\mathrm{st}}\right) \times\left(\left(m^{\prime}\right)_{\mathrm{fuel}, \mathrm{a} \%}\right) / \phi
$$

\subsection{Estimation of the Laminar Flame Velocity}

The laminar flame velocity is a quantity that accounts for the thermo-chemical state of the combustible mixture moving into the burning zone. The most classical correlations for laminar flame velocity employ similar power-function expressions to correlate the unburned gas temperature, pressure, and mixture diluent fraction with measured laminar flame velocities by using multicomponent hydrocarbons and alcohols, which are similar to automotive fuels. The most common correlations used to estimate the laminar flame velocity in spark-ignition environments are of the following type $[13,16,30,31,40-43]$ :

$$
S_{\mathrm{L}}=S_{\mathrm{L}, \mathrm{ref}} \times\left(T_{\mathrm{u}} / T_{\text {ref }}\right)^{\mathrm{a}} \times\left(P / P_{\text {ref }}\right)^{\mathrm{b}} \times\left(1-d \times x^{\mathrm{c}}\right)
$$

where $\left(T_{\mathrm{u}}\right)$ and $(P)$ are the unburned gas temperature and the cylinder pressure, respectively. The reference parameters, $T_{\text {ref }}=298 \mathrm{~K}$ and $P_{\text {ref }}=1 \mathrm{~atm}$, represent the conditions at which the reference laminar flame velocity $\left(\mathrm{S}_{\mathrm{L}, \mathrm{ref}}\right)$ is calculated. The reference laminar flame velocity depends only on the type of fuel and also on the actual fuel equivalence ratio of the mixture $(\phi)$. The constants (a) and (b) are also functions of the mixture fuel equivalence ratio only. As known, the presence of diluents in the unburned mixture restrains the spread of the flame front. For the estimation of the actual laminar flame velocity (Equation (7)), the term $\left(1-d \times x^{\mathrm{c}}\right)$ represents the fractional reduction in the laminar flame speed due to the existence in the mixture of diluents fraction $(x)[13,16,30,31,40-43]$.

\section{Model Validation}

As mentioned in previous section, the model used in this study was an existing two-zone phenomenological combustion model, which simulates the closed part of the operating cycle of a conventional, 4-stroke, SI engine. The basic philosophy of the model has not been modified at all. However, in order to allow the model to be used in the present study, some modifications have been made, which have to do with the estimation of some critical parameters, such as the cylinder charge conditions at inlet valve closure event, the air and fuel mass flow rates, and the laminar flame velocity. 
The procedure that was adopted for the estimation of these parameters is given in detail in respective sub-paragraphs of the previous section. As previously mentioned, the experimental data obtained from [14] were used only to calibrate and also to evaluate the predictive ability of the proposed model. The main geometrical and operational data related to the simulated engine are presented in Table 2 [14], where CA means crank angle, BTDC means before top dead center, ABDC means after bottom dead center, and ATDC means after top dead center.

Table 2. Basic geometrical and operational data of the test engine.

\begin{tabular}{cc}
\hline Engine & Datsu LT 200 \\
\hline Type & 4-stroke, SI engine \\
Number of cylinders (-) & 1 \\
Cylinder bore $(\mathrm{m})$ & 0.065 \\
Piston stroke $(\mathrm{m})$ & 0.054 \\
Compression ratio $(-)$ & $8.5: 1$ \\
Displacement volume $\left(\mathrm{m}^{3}\right)$ & 0.00018 \\
Max. Power $(\mathrm{kW}) /$ Speed $(\mathrm{rpm})$ & $2.5 / 3800$ \\
Fuel system & Carburetor \\
Cooling system & Air cooled \\
Normal spark timing & 23 deg CA BTDC \\
Inlet valve closure (IVC) & 74 deg CA ABDC \\
Exhaust valve opening (EVO) & 136 deg CA ATDC \\
\hline
\end{tabular}

According to [14], the experimental results used in the present contribution correspond to engine operation at constant speed $(N=2400 \mathrm{rpm})$ and full loading conditions $(a=100 \%)$, at constant spark advance (i.e., NSA $=23 \mathrm{deg}$ CA BTDC) and constant fuel equivalence ratio $(\phi=1.01)$. In the present wok, these engine operating conditions are referred to as "Normal Engine Operating Point" (i.e., NEOP).

For the NEOP engine operating point, two sets of experimental measurements were used in the present work. The first set of the experimental measurements corresponds to engine operation at NEOP under gasoline fuel operating mode, while the second one corresponds to engine operation under neat-ethanol mode at the same NEOP operating point. For each one of the aforementioned two sets of measurements, use was made of experimental data corresponding to the engine volumetric efficiency $\left(\eta_{\mathrm{v}}\right)$, the cylinder pressure and rate of heat release diagrams, the power output $\left(P_{\mathrm{e}}\right)$, the brake specific fuel consumption (bsfc), and the specific $\mathrm{NO}(\mathrm{spNO})$ and specific $\mathrm{CO}(\mathrm{spCO})$ emissions. All these experimental data are summarized in Table 3 [14], where $\left(M_{\sigma}\right)$ denotes the engine torque. As mentioned before, all the experimental data mentioned previously were used as a basis to calibrate and evaluate the predictive ability of the proposed model. It must be stated here that the change of engine operating mode from G100 to E100 is accompanied with an increase of the aspirated air mass flow rate (increase of engine volumetric efficiency). Thus, in order to maintain constant the fuel-air ratio of the mixture, a larger amount of fuel is required. The appropriate increase of the fuel supply is taken place in the engine's carburetor by using a conical screw.

Table 3. Experimental data for the operation of engine "Datsu LT 200", either with gasoline (G100) or with ethanol (E100), at normal engine operating point (NEOP).

\begin{tabular}{cccccccccccc}
\hline \multirow{2}{*}{$\begin{array}{c}\text { Fuel Operating } \\
\text { Mode }\end{array}$} & $\begin{array}{c}\text { Throttle } \\
\text { Opening }\end{array}$ & $\boldsymbol{\varphi}$ & $\boldsymbol{P}_{\mathbf{e}}$ & $\boldsymbol{N}$ & $\eta_{\mathbf{v}}$ & NSA & $\boldsymbol{M}_{\boldsymbol{\sigma}}$ & bsfc & NO & CO \\
\cline { 2 - 11 } & $\mathbf{\%}$ & - & $\mathbf{k W}$ & $\mathbf{r p m}$ & $\mathbf{\%}$ & $\mathbf{d e g}$ CA BTDC & $\mathbf{N m}$ & $\mathbf{g} / \mathbf{k W h}$ & $\mathbf{g} / \mathbf{k W h}$ & $\mathbf{g} / \mathbf{k W h}$ \\
\hline Gasoline-G100 & 100 & 1.009 & 2.63 & 2400 & 73.1 & 23 & 10.48 & 279 & 4.9 & 43.5 \\
Ethanol-E100 & 100 & 1.015 & 2.70 & 2400 & 75.9 & 23 & 10.76 & 453 & 2.6 & 36.9 \\
\hline
\end{tabular}


In Figure $1 \mathrm{a}, \mathrm{b}$ the comparison between computed and experimental cylinder pressure and heat release traces is given, corresponding to engine operation at NEOP engine operating point, either under conventional gasoline (G100) or under neat-ethanol (E100) fuel operating modes, respectively.

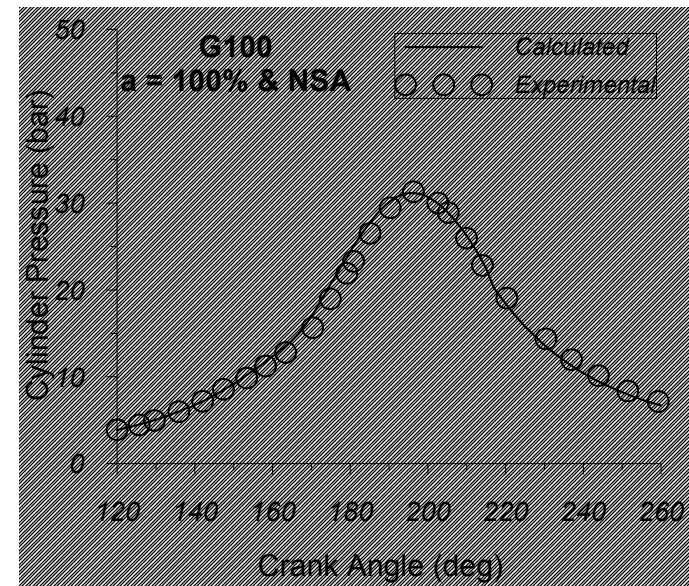

(a)

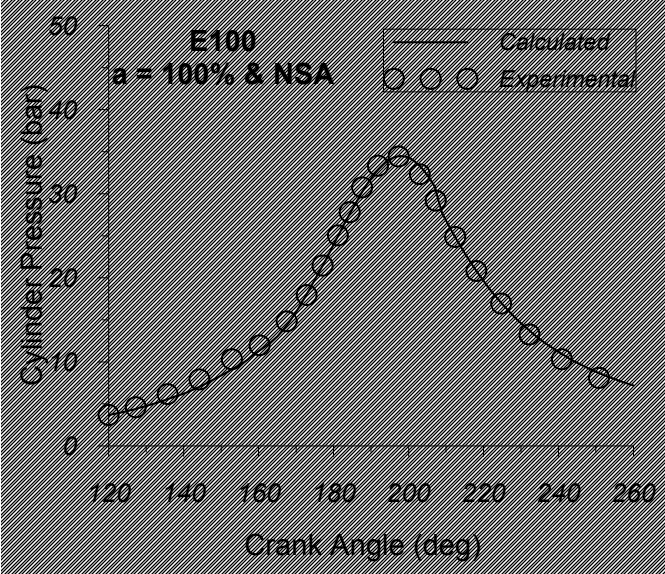

(c)

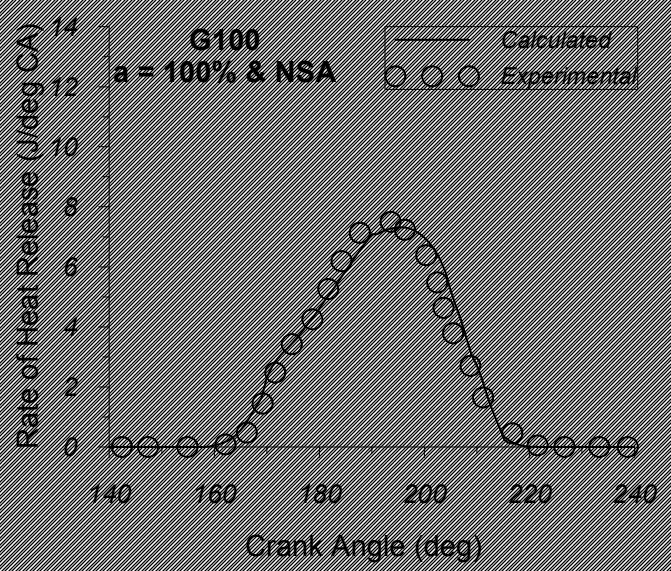

(b)

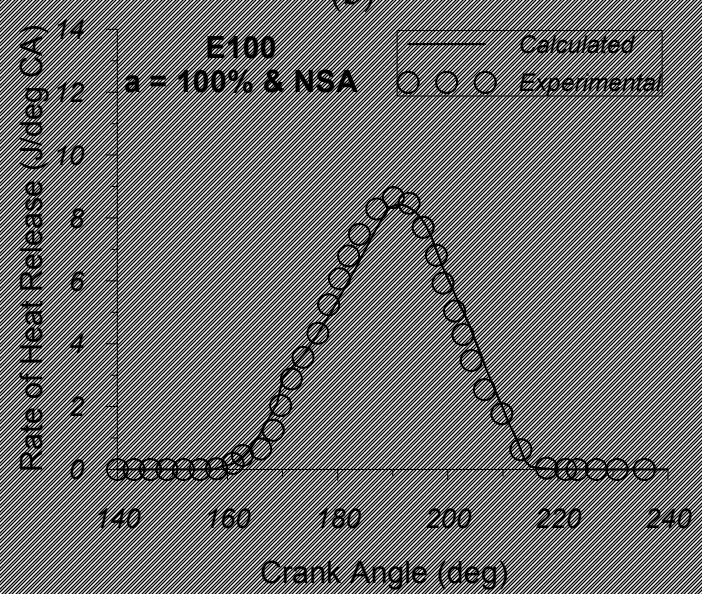

(d)

Figure 1. Comparison between experimental and computed cylinder pressure and rate of heat release traces of the "DatsuL200" engine, running at 100\% of full engine load and $2400 \mathrm{rpm}$ engine speed with normal spark timing, operating under G100 (a,b); or E100 (c,d); fuel modes.

By observing these figures, a very good coincidence is revealed between experimental and calculated cylinder pressure and heat release traces. This discloses the ability of the specific model to predict adequately both the cylinder pressure diagram and the combustion mechanism, for a light-duty, naturally aspirated, spark-ignited engine, running at full load conditions either under conventional gasoline or neat-ethanol fuel operating mode, as well. It must be stated here that for each fuel operating mode, the simulation model has been calibrated at NEOP engine operating point by using the available experimental results. Moreover, following the model calibration, the values of the model constants are held constant for the whole of the test cases considered in the present study.

The comparison between experimental and calculated values of brake power output $\left(P_{\mathrm{e}}\right)$ and bsfc, for both the fuel operating modes (i.e., G100 and E100), at the same engine operating point (i.e., NEOP), is given in Figure 2a,b. 


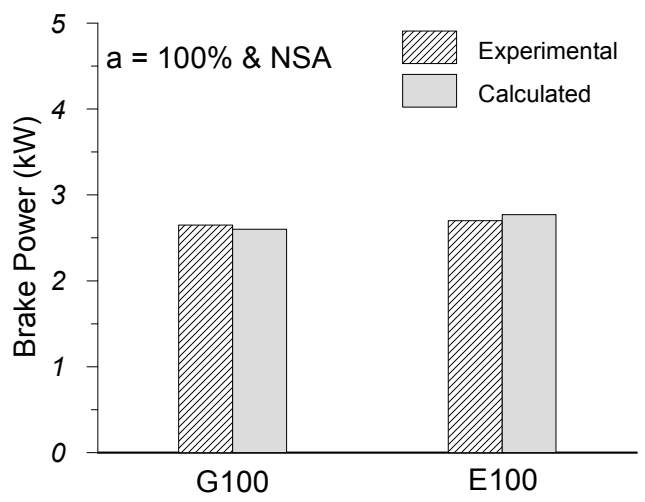

(a)

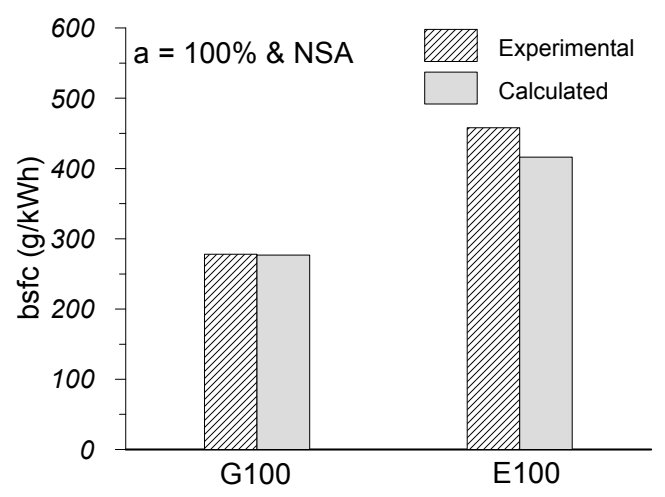

(b)

Figure 2. Comparison between calculated and experimental values of brake power output (a); and brake specific fuel consumption (b); of the "DatsuL200" engine running at $100 \%$ of full engine load and 2400 rpm engine speed with normal spark timing, under G100 or under E100 fuel operating modes.

By observing Figure 2a, it is revealed that the proposed model manages to predict with a very good match the experimental values, thus revealing the ability of the specific model to predict adequately the brake power output of a light-duty, spark-ignited engine, operating at full load conditions either under gasoline or neat-ethanol, as well. Moreover, by observing Figure 2b, it is shown that for both fuel operating modes (G100 and E100) examined, the proposed model predicts with relatively good accuracy the experimental brake specific fuel consumptions. Specifically, it is observed that the use of neat-alcohol as a full substitute of gasoline results in an increase of the brake specific fuel consumption. This is due to the lower heating value that alcohol has, as compared to the respective one of gasoline. Finally, it must be stated here that according to [14], the experimental brake specific fuel consumption is estimated from the measured brake power output and the measured fuel consumption. The comparison between experimental and calculated values of specific $\mathrm{NO}$ and $\mathrm{CO}$ concentrations, for both fuel operating modes (i.e., G100 and E100) at the same engine operating point (i.e., NEOP), is given in Figure $3 \mathrm{a}, \mathrm{b}$ respectively.

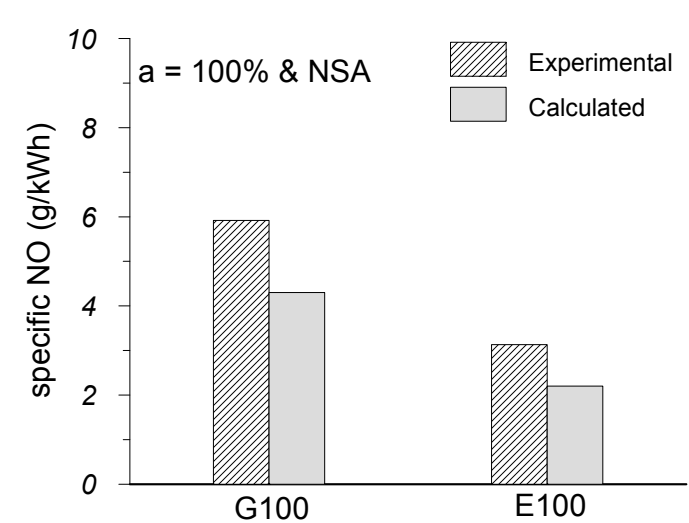

(a)

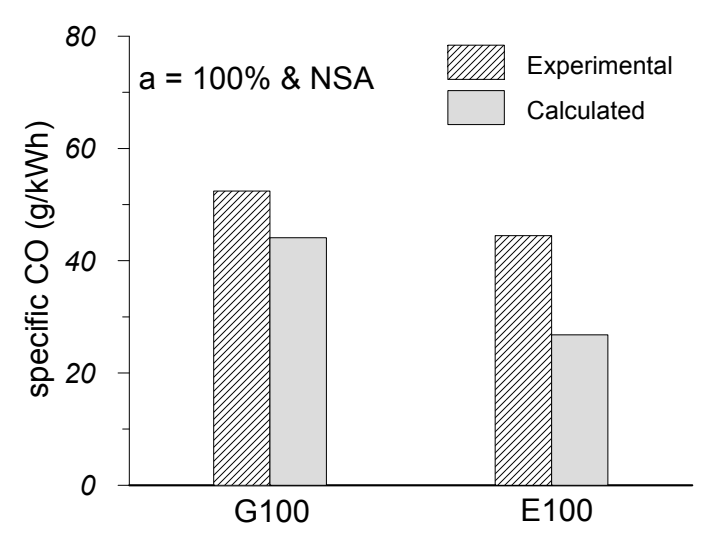

(b)

Figure 3. Comparison between calculated and experimental values of specific NO concentration (a); and specific CO concentration (b); of the "DatsuL200" engine running at 100\% of full engine load and 2400 rpm engine speed with normal spark timing, under G100 or under E100, fuel operating modes.

By observing these figures, it is revealed that for each one of the fuel operating modes examined herein, the calculated values are underestimated compared to the experimental ones. But, this is usual for a two-zone model, as it under-predicts the burning zone temperature, which is a factor that affects 
seriously both the $\mathrm{NO}$ and the $\mathrm{CO}$ formation mechanisms. In any case, it is revealed that the model manages to predict with adequate accuracy the trends of specific $\mathrm{NO}$ and $\mathrm{CO}$ emissions.

Consequently, by comparing both the experimental and the theoretical results, it is revealed that despite the small differences observed between the measured and calculated absolute values, which are primarily attributed to the inherent limitations of a phenomenological two-zone model, the simulation model manages to predict with satisfactory accuracy the trend of engine performance characteristics and pollutant emissions, when the conventional liquid fuel (i.e., gasoline) is fully substituted by an alcohol-based liquid fuel (i.e., ethanol). Hence, the specific phenomenological model could be used to perform a parametric study concerning the effect of spark timing on the performance and pollutant emissions of a light-duty, spark-ignited engine, operating either under gasoline (G100) or under neat-butanol (B100) or under neat-ethanol (E100) fuel operating mode, at full ( $a=100 \%$ ) or at partial $(a=60 \%)$ loading conditions, respectively.

\section{Test Cases Examined}

As previously mentioned, in the present work an effort is made to predict the relative impact of spark timing and the type of fuel (gasoline, butanol, ethanol) on the performance and pollutant emissions of a light-duty, spark-ignited engine, operating either at full or at partial loading conditions, respectively. Therefore, at two different engine loads corresponding to $60 \%$ and $100 \%$ of full engine load and at $2400 \mathrm{rpm}$ engine speed, the full gasoline replacement by butanol (i.e., B100) and then by ethanol (i.e., E100) was initially investigated, regarding the performance characteristics and pollutant emissions of the aforementioned spark-ignited engine, operating at $2400 \mathrm{rpm}$ engine speed and constant fuel equivalence ratio $(\phi=1.01)$ for normal spark advance (i.e., NSA $=23$ deg CA BTDC).

Furthermore, for each one of the three different fuel operating modes (G100, B100, E100), the effect of spark timing on the performance characteristics and pollutant emissions was examined. Therefore, at the two different engine loads, corresponding to $60 \%$ and $100 \%$ of full engine load and at $2400 \mathrm{rpm}$ engine speed, for each one of the aforementioned fuel operating modes, the spark timing was changed by 3 degrees crank angle after the normal spark timing point (i.e., $\mathrm{SA}=23-3=20 \mathrm{deg}$ CA BTDC), and by 3 degrees crank angle before the normal spark timing (i.e., $\mathrm{SA}=23+3=26 \mathrm{deg}$ CA BTDC). As far as the ignition timing is concerned, it should be stated here that the knock sub-model used was calibrated by employing the available experimental data corresponding to engine operation at full engine loading conditions, either under the G100 or the E100 fuel operating mode, respectively.

\section{Results and Discussion}

In this section, the predictive capabilities of the phenomenological model are explored. The predicted effects of the two critical parameters (i.e., the start of ignition and the type of fuel) on some basic performance characteristics and pollutant emissions of a conventional SI engine are examined, for two engine operating points corresponding to $60 \%$ and $100 \%$ of full engine load and at $2400 \mathrm{rpm}$ engine speed. Moreover, before looking into the results, it should be noted here that the terms G100, B100 and E100 represent the neat gasoline, the neat butanol and the neat ethanol operating modes, respectively.

\subsection{Cylinder Pressure and Rate of Heat Release}

Figure $4 \mathrm{a}$, b provides the predicted cylinder pressure and rate of heat release (ROHR) traces, for the three engine fuelling operating modes examined herein (i.e., G100, B100, E100), at 2400 rpm engine speed and two different engine loading points (i.e., $60 \%$ and $100 \%$ of full engine load), under normal spark timing (i.e., NSA $=23$ deg CA BTDC). 


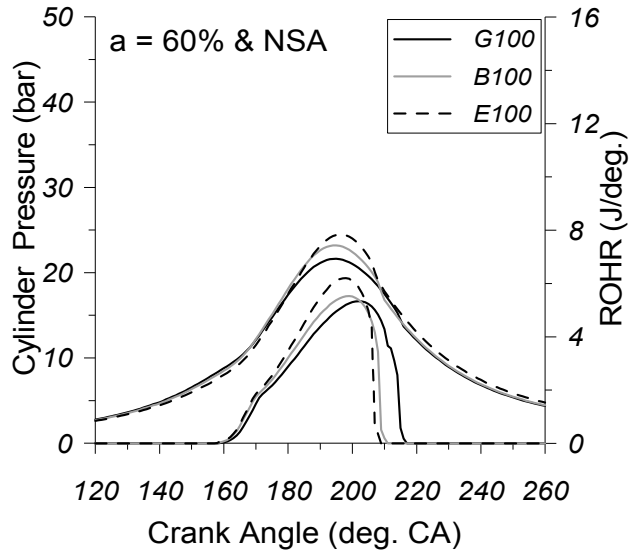

(a)

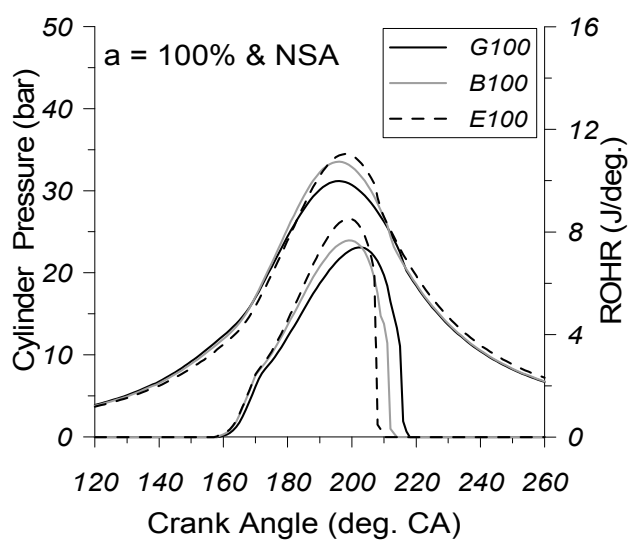

(b)

Figure 4. Calculated cylinder pressure and heat release rate traces for G100, B100 and E100 fuel operating modes, normal spark timing at $2400 \mathrm{rpm}$ and $60 \%$ load (a); and $2400 \mathrm{rpm}$ and 100\% load (b).

By observing these figures, it is revealed that for each one of the three fuels operating modes (G100, B100, E100) examined herein, the engine load affects the peak cylinder pressure without having a serious effect on the shape of both the cylinder pressure and heat release rate traces. Specifically, it is revealed that for each one of the G100, B100 and E100 operating modes, the increase of engine load with constant spark timing and engine speed seems to lead to a more intense rise of the cylinder pressure, especially during the initial stages of the combustion process, hence resulting in an increase of both the maximum cylinder pressure and the maximum burning zone temperature. It should be stated here that in this type of engine the adjustment of the engine load is achieved by throttling the mass flow rate of the aspirated air-fuel mixture, so that at each engine loading condition the fuel equivalence ratio remains essentially constant. Thus, for each one of the three fuel operating modes (G100, B100, E100), the increase of engine load, under constant fuel equivalence ratio, is accompanied by a simultaneous increase in both the aspirated air mass flow rate and the fuel consumption, which justifies the increase of the heat released observed during the combustion process, a fact that leads to an increase of the maximum cylinder pressure.

As far as the effect of the type of fuel on cylinder pressure diagram is concerned, it is revealed that at the same combination of engine load and spark timing, the cylinder pressure during the compression stroke, observed under both the B100 and the E100 operating modes, diverges slightly from the respective values observed under the G100 mode. This may be attributed to the higher heat of vaporization an alcohol fuel has as compared to the respective one of gasoline, a fact that affects negatively (i.e., decrease) the cylinder charge temperature corresponding to the inlet valve closure timing. Moreover, the higher heat of vaporization of an alcohol has a positive effect (increase) on the specific heat capacity an alcohol-air mixture has, which also has a slightly negative effect (slight decrease) on the cylinder charge temperature. However, after the initiation of combustion, it is revealed that the engine operation either under the B100 or the E100 fuel operating modes, seems to have a positive effect (i.e., becomes more intense) on the rate of the cylinder pressure rise, a fact that becomes more pronounced during the initial stages of the combustion process. This justifies the fact that both the maximum cylinder pressure and the maximum burning zone temperatures observed, either under the B100 or the E100 operating mode, are slightly higher as compared to the respective values observed under the conventional G100 operating mode. Regarding the effect of the type of fuel on the heat release rate diagram, it is revealed that at the same engine operating point (load and engine speed) without altering the ignition timing, during the initial stages of the combustion process, the rate of heat release observed, either under the B100 or under the E100 operating mode, becomes more intense than that of the conventional gasoline operation. This seems to be attributed to the higher turbulent 
flame propagation velocities that both alcohol-fuels (butanol and ethanol) have, as compared to the respective velocity of the gasoline.

As known [30-32], the turbulent flame propagation velocity depends on the laminar flame speed of the fuel-air mixture, which is affected by both the cylinder charge conditions (pressure and temperature) and the reference flame speed of the stoichiometric fuel-air mixture. Looking at the data given in Table 1, it is revealed that both alcohols used herein have a higher stoichiometric reference flame speed than gasoline, while at the same time the stoichiometric reference flame speed of ethanol is higher than the respective one of butanol. On the other hand, for both the B100 and the E100 operating modes, the cylinder charge conditions corresponding to the initiation of combustion instant, are slightly lower to the respective values observed under the conventional operation (G100), which is a fact that restrains the laminar flame speed of the air-fuel mixture. However, by examining the calculated results, it is revealed that during the initial stages of combustion, the effect of the reference flame speed of the stoichiometric air-fuel mixture seems to be more pronounced on the burning rate, as compared to the respective effect that the cylinder charge conditions have. The latter arguments justify the more intense rise of the heat release rate observed during the initial stages of combustion under both the B100 and the E100 operating modes, in comparison to the rise of the respective rate observed under the conventional G100 operating mode.

Figure $5 \mathrm{a}-\mathrm{f}$ provide the predicted cylinder pressure and heat release traces, for various spark timings (i.e., $\mathrm{SA}=26,23$ and $20 \mathrm{deg}$ CA BTDC), corresponding to $2400 \mathrm{rpm}$ engine speed and two different engine loading points (i.e., $60 \%$ and $100 \%$ of full engine load), under the G100 (Figure $5 a, b$ ), the B100 (Figure 5c,d), and the E100 (Figure 5e,f) fuel operating modes, respectively. Looking at these figures, it is revealed that the ignition timing affects both the cylinder pressure history and the rate of heat release. Specifically, it is shown that the advance of the spark timing relative to TDC position seems to enhance the rate of the cylinder pressure rise, especially during the initial stages of the combustion process. This is due to the fact that during the specific phase, the increment of the energy release rate combined with the increase of the cylinder charge temperature, result in the increase of the cylinder pressure to become more pronounced. Moreover, concerning the effect of the spark timing on the heat release rate, it is observed that a slight alteration of the spark timing does not seem to affect seriously the shape of the combustion rate.

However, a slight advance of spark timing relative to normal spark advance results to a slightly earlier initiation of the combustion, while, at the same time, it seems to enhance the rate of the heat release rise observed during the initial stages of combustion. This is due to the fact that the spark timing advance leads to an increase of the fuel mass burned before the TDC position, a fact that affects positively both the existence and the fast spread of the flame front. By observing Figure $4 a, b$, it is revealed that for the same spark timing and constant air to fuel excess ratio, the full replacement of gasoline either by butanol or ethanol leads to a slight increase of the maximum cylinder pressure. Moreover, by examining Figure $5 \mathrm{a}-\mathrm{f}$, it is observed that the advance of ignition timing relative to TDC position leads to an increase of the maximum cylinder pressure. At part load the increase does not seem to be so severe, while at full load the effect of the ignition advance seems to be more intense. 


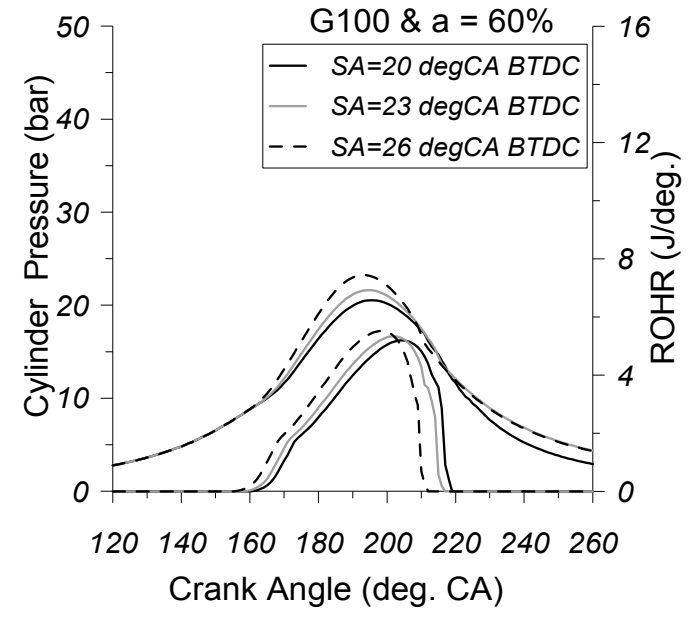

(a)

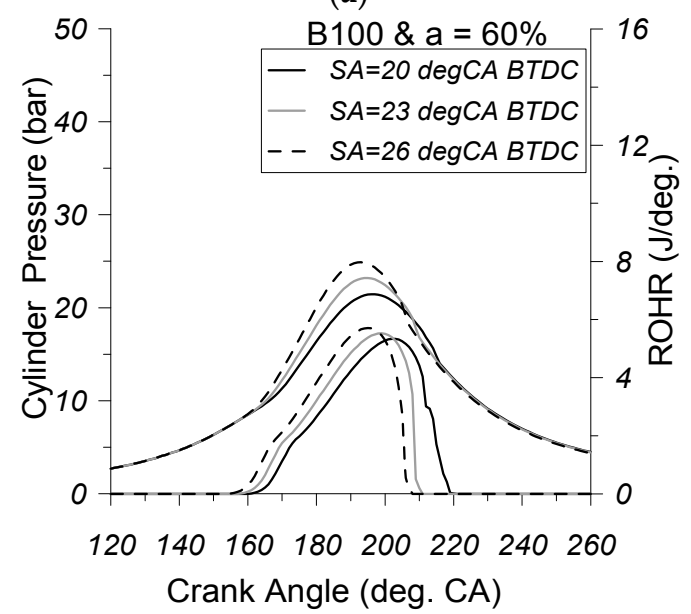

(c)

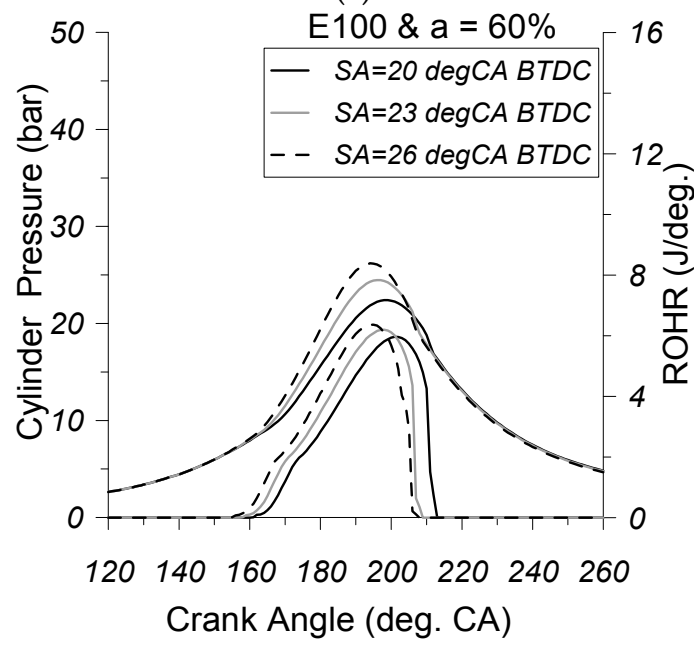

(e)

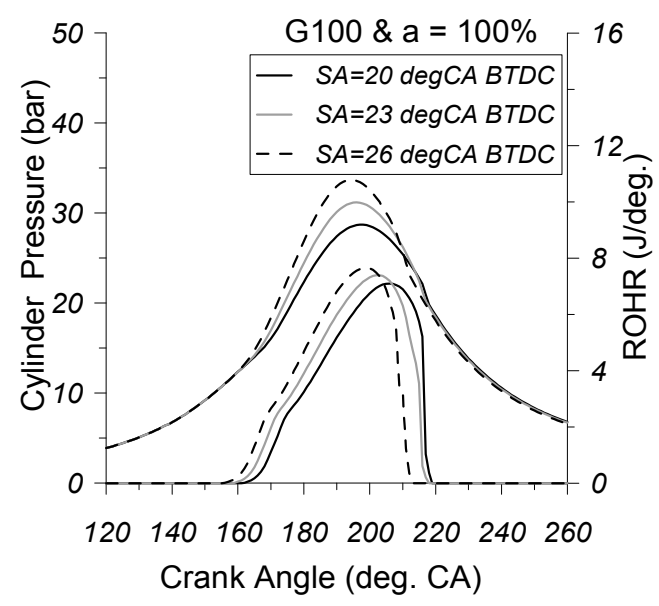

(b)

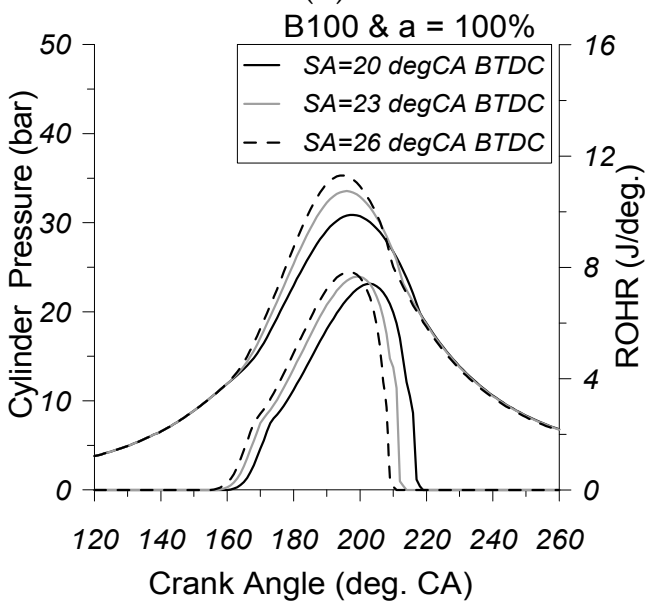

(d)

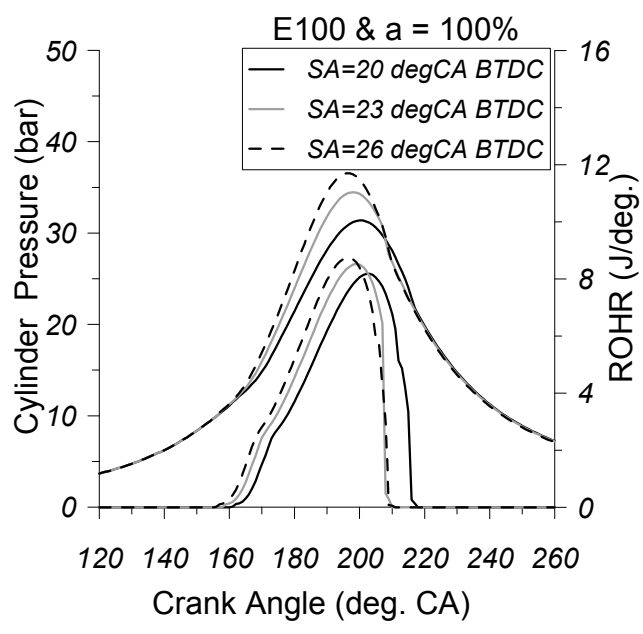

(f)

Figure 5. Calculated cylinder pressure and heat release traces for various spark timings, with G100 at $2400 \mathrm{rpm}$ and $60 \%$ load (a); and $2400 \mathrm{rpm}$ and $100 \%$ load (b); with B100 at $2400 \mathrm{rpm}$ and $60 \%$ load (c); and $2400 \mathrm{rpm}$ and 100\% load (d); and with E100 at $2400 \mathrm{rpm}$ and 60\% load (e); and $2400 \mathrm{rpm}$ and $100 \%$ load (f). 


\subsection{Duration of Combustion}

In Figure $6 a, b$, the variation of duration of combustion with spark timing (SA) is given, under the G100, B100 and E100 operating modes, at $2400 \mathrm{rpm}$ engine speed for $60 \%$ and $100 \%$ of full engine loading conditions, respectively. It should be noted here that for both engine loading conditions examined herein (i.e., $60 \%$ and $100 \%$ of full engine load) and for the three operating modes (i.e., G100, $\mathrm{B} 100$ and E100), the fuel equivalence ratio remains constant and equal to $\phi=1.01$.

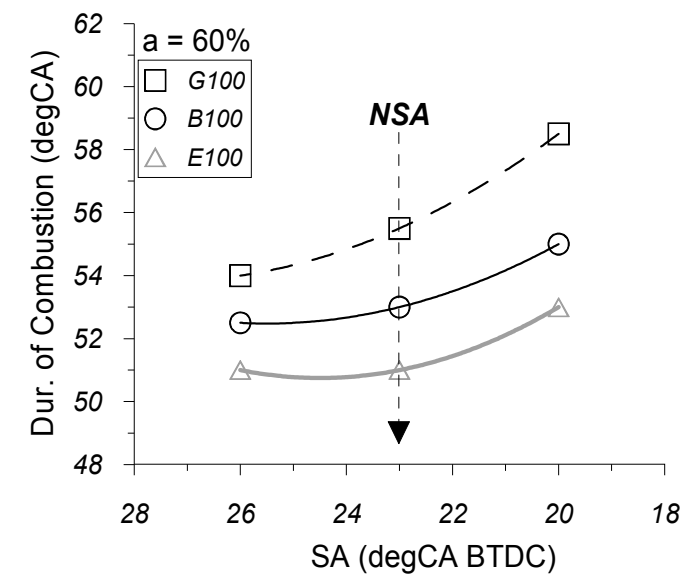

(a)

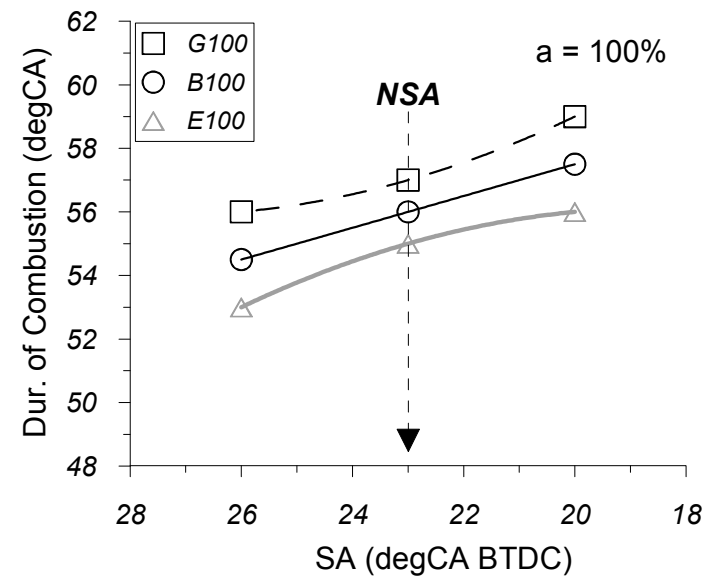

(b)

Figure 6. Variation of the calculated duration of combustion as a function of the spark advance for G100, B100 and E100 fuel operating modes, at $2400 \mathrm{rpm}$ engine speed and 60\% of full load (a); and $2400 \mathrm{rpm}$ engine speed and $100 \%$ of full load (b).

By observing these figures, it is revealed that for the same type of fuel, keeping constant the spark timing, the increase of engine load is accompanied by a slight prolonging of the duration of combustion. This may be attributed to the fact that the increase of engine load is accompanied by an increase in the fuel consumption, while, at the same time, the burning rate does not appear to be affected significantly, since the variation of the turbulence flame propagation velocity seems to be almost negligible.

As far as the effect of spark timing on the duration of combustion is concerned, it is revealed that for the same operating mode, by keeping constant the engine load, the advance of ignition timing leads to a shorter duration of combustion. This effect seems to become more evident at high engine loading conditions. This may be attributed to the fact that by advancing the ignition timing relative to TDC position, combustion initiates earlier and there is an increase of the fuel mass burned before TDC position. The latter affects positively (enhances) the spread of the flame speed, thus causing the enhancement of the combustion rate and shortening of the combustion duration.

Regarding the effect of the type of fuel on the duration of combustion, it is shown that for both loads examined and for the same spark timing, the duration of combustion observed under the G100 operating mode is slightly higher when compared to the respective values observed under both the B100 and the E100 operating modes. Furthermore, the duration of combustion observed under the B100 operating mode seems to be also slightly longer as compared to the respective value observed under the E100 operation. Despite the fact that the engine operation at constant engine load, either under the B100 or under the E100 operating modes, has to be accompanied by an increase in fuel consumed, as compared to the respective conventional gasoline operation, the improvement of the turbulence flame propagation velocity observed under both the B100 and the E100 fuel operating modes seems to affect positively the quality of combustion, thus resulting in slight shorter duration of combustion. 
Despite the fact that for the same engine load conditions the full replacement of gasoline with an alcohol has to be accompanied by a higher amount of fuel consumed (owing to the lower heating value of an alcohol as compared to that of gasoline), the slightly shorter, as compared to the G100 operation, duration of combustion observed under either the B100 or the E100 operating modes, is justified by the enhancement of the turbulence flame propagation velocity, observed (especially) during the initial stages of combustion.

\subsection{Indicated Specific Fuel Consumption}

Figure $7 \mathrm{a}, \mathrm{b}$ illustrate the variation of the calculated indicated specific fuel consumption (isfc) as a function of spark timing, under the G100, B100 and E100 engine operating modes, respectively. Predictions are given at $2400 \mathrm{rpm}$ engine speed for $60 \%$ and $100 \%$ of full engine load, respectively.

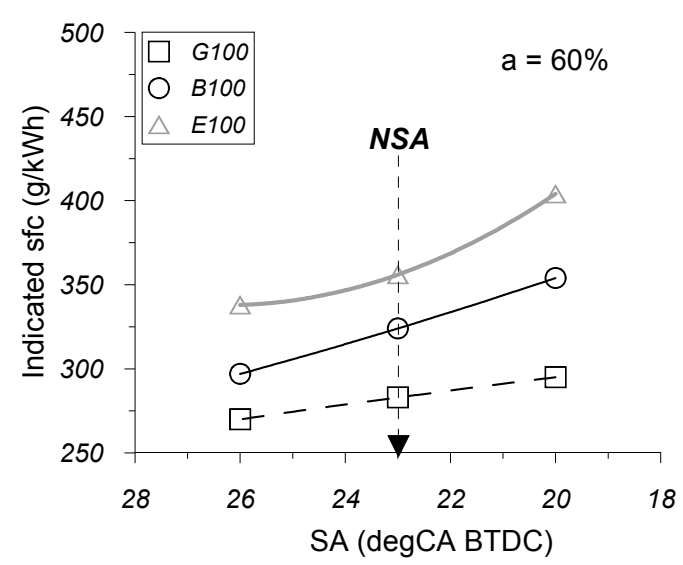

(a)

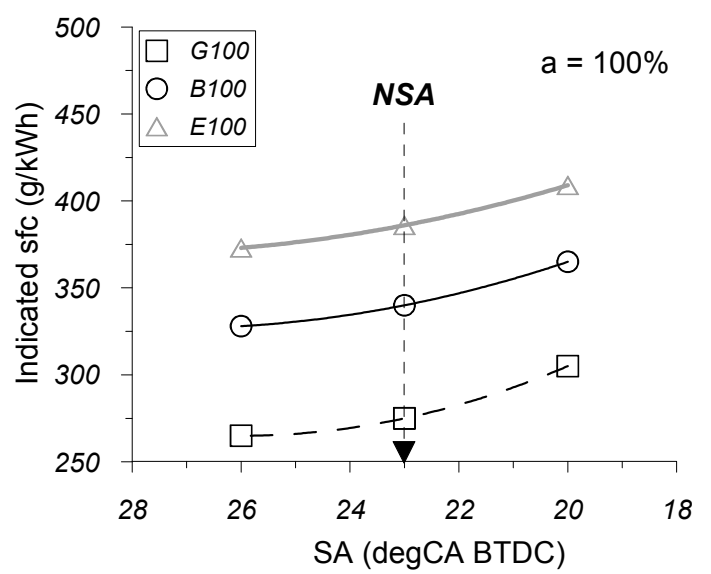

(b)

Figure 7. Variation of the calculated indicated specific fuel consumption as a function of the spark advance for G100, B100 and E100 fuel operating modes, at $2400 \mathrm{rpm}$ engine speed and $60 \%$ of full load (a); and 2400 rpm engine speed and 100\% of full load (b).

By observing these figures, it is revealed that for the same engine operating point (combination of load and spark timing), the full replacement of gasoline either by butanol or by ethanol leads to an increase of the isfc, thus resulting in a deterioration of the indicated engine thermal efficiency. Despite the slight increase in the indicated power output recorded by changing the fuel from gasoline to butanol or ethanol, the deterioration observed on the calculated isfc may be primarily attributed to the considerably lower low heating values that both alcohols have (used in the present study), as compared to the respective heating value of gasoline. Therefore, for constant fuel equivalence ratio at the same combination of load and spark timing, the engine operation either with butanol (B100) or ethanol (E100) has to be accompanied by higher amounts of fuel consumptions, as compared to the respective amounts recorded with the G100 operating mode, hence justifying the increase observed in the calculated indicated specific fuel consumption.

Concerning the effect of spark timing on the isfc, it is revealed that the advance of the initiation of combustion leads to a slight increase of the indicated specific fuel consumption. Taking into account the fact that the alteration of ignition timing does not affect the amount of fuel consumed, this effect may be primarily attributed to the slight decrease of the indicated power output calculated for the specific test cases. This effect seems to become more sensible at high engine loading conditions. But, consequently, ignition timing does not appear to have an essential effect on the indicated engine efficiency.

Finally, as far as the effect of engine load on isfc is concerned, it is observed that for each one of the three fuel operating modes (G100, B100, E100) examined herein, the engine operation seems to be slightly more efficient at high engine loading conditions. This may be attributed to the fact that 
for the specific type of engine, the increase of engine load, under constant fuel equivalence ratio, is accompanied by a slightly more intense increase of the indicated power output as compared to the increase recorded for the required fuel consumption.

\subsection{Specific NO Concentration}

Figure $8 \mathrm{a}, \mathrm{b}$ depicts the variation of the calculated indicated specific NO concentration (spNO) versus spark timing. The results correspond to $60 \%$ and $100 \%$ of full engine load conditions, for the G100, B100 and E100 operating modes, at 2400 rpm engine speed.

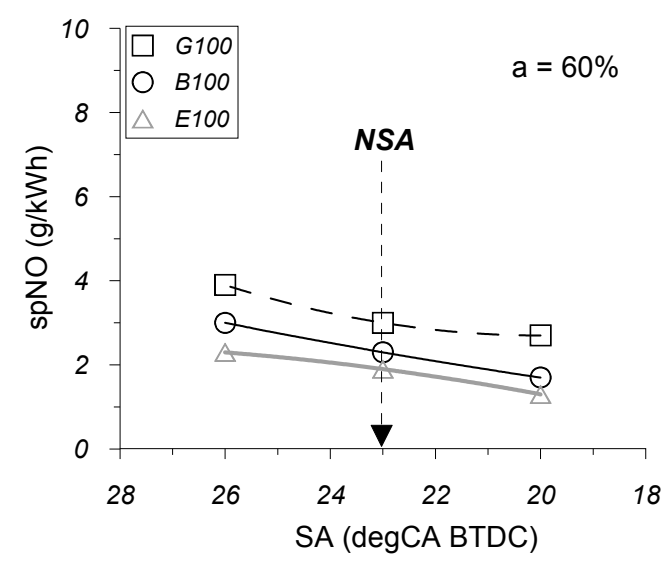

(a)

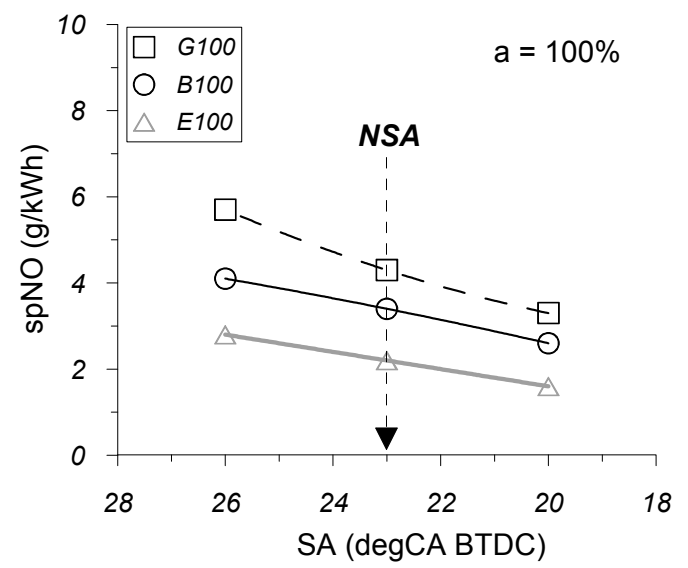

(b)

Figure 8. Variation of the calculated indicated specific NO concentration as a function of the spark advance for G100, B100 and E100 fuel operating modes, at $2400 \mathrm{rpm}$ engine speed and $60 \%$ of full load (a); and 2400 rpm engine speed and $100 \%$ of full load (b).

By observing these figures, it is revealed that for each one of the three fuels used in the present work at each one of the spark timings examined herein, the increase in engine loading conditions without alteration of the fuel equivalence ratio, leads to an almost negligible variation of the calculated indicated specific NO concentrations. As mentioned before the increase of engine load results to an increase of the indicated power output. Moreover, the load increment enhances the NO formation mechanism, since the increase of engine load is accompanied by an increase of the maximum burning zone temperature [30-32].

Concerning the effect of ignition timing on the calculated indicated specific NO emissions (Figure 8a,b), it is revealed that for both engine loads and for each one of the three fuel operating modes (G100, B100 and E100), the advance of the ignition timing relative to the TDC position results in an increase of the calculated indicated specific NO concentrations. This may be primarily attributed to the fact that the spark timing advance leads to an increase of the fuel mass burned before the TDC position, a fact that enhances both the fuel combustion rate and the temperature of the burning zone. The latter favors considerably the NO formation mechanism [30-32].

Regarding the effect of the type of fuel on the indicated specific NO concentration (Figure 8a,b), it is revealed that for both engine loads and for constant spark timing, the full replacement of gasoline either by butanol or by ethanol fuel, leads to a slight decrease of the calculated indicated specific $\mathrm{NO}$ concentrations. As known, the indicated specific NO concentration is proportional to the NO formed concentration and inversely proportional to the indicated power output. By examining the model results, it is observed that with the complete replacement of the conventional gasoline fuel by an alcohol, a slight increase in the calculated indicated power output is recorded. Furthermore, by observing the variation of the calculated burning zone temperature, it is revealed that the engine operation, either under the B100 or under the E100 operating modes, may lead to a slightly higher maximum burning zone temperature, as compared to the one observed under the G100 operating 
mode. But, at the same time, it seems to affect negatively the reduction rate of the burning zone temperature after the TDC position, hence leading to a more intense reduction of the burning zone temperature. This phenomenon seems to become more pronounced during the expansion phase, where the burning zone temperature observed under the G100 operating mode seems to become slightly higher as compared to the respective values observed under the B100 and the E100 fuel operating modes. By taking into account the aforementioned observations and also the fact that $\mathrm{NO}$ formation rate depends on the change of the burning zone temperature [30-32], it is justified that the calculated $\mathrm{NO}$ concentration formed under the B100 or E100 operating modes is slightly lower than the respective concentration calculated under the conventional G100 operating mode.

\subsection{Specific CO Concentration}

Figure $9 \mathrm{a}, \mathrm{b}$ depicts the variation of the calculated indicated specific $\mathrm{CO}$ concentration (spCO) versus spark timing. The results correspond to $60 \%$ and $100 \%$ of full engine load conditions, for the G100, B100 and E100 operating modes, at 2400 rpm engine speed.

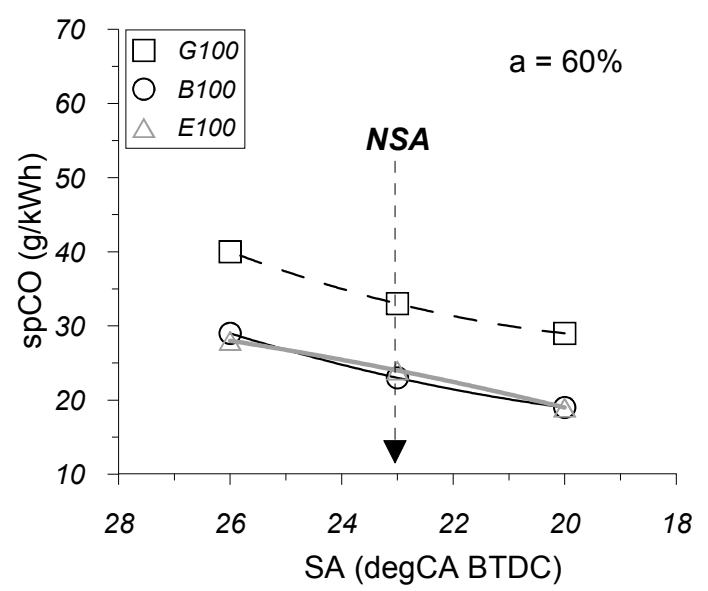

(a)

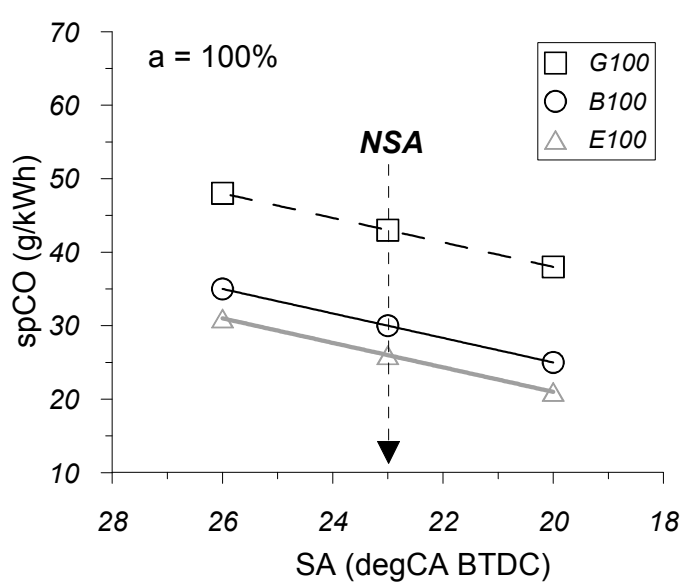

(b)

Figure 9. Variation of the calculated indicated specific $\mathrm{CO}$ concentration as a function of the spark advance for G100, B100 and E100 fuel operating modes, at $2400 \mathrm{rpm}$ engine speed and $60 \%$ of full load (a); and $2400 \mathrm{rpm}$ engine speed and 100\% of full load (b).

As far as the effect of engine load on the indicated specific CO concentration is concerned, it is observed that for each one of the three fuels used in the present work at each one of the spark timings examined herein, the increase in engine loading conditions, without alteration of the fuel equivalence ratio, leads to a slight increase of the calculated indicated specific $\mathrm{CO}$ concentrations. As mentioned previously, the increase of engine load results to an increase of the indicated power output. But, at the same time, it is accompanied by an increase of the maximum burning zone temperature, a factor that enhances significantly the $\mathrm{CO}$ formation mechanism [30-32].

Concerning the effect of spark timing on the indicated specific $\mathrm{CO}$ concentration, it is observed that for both loads examined and for each one of the three types of fuels used herein, the advance of spark timing seems to have a negative effect (i.e., slight increase) on the calculated indicated specific $\mathrm{CO}$ concentration. As previously mentioned, spark timing advance leads to an increase of the fuel mass burned before the TDC position, a fact that enhances both the fuel combustion rate and the temperature of the burning zone. The latter considerably favors the CO formation mechanism [30-32]. At the same time, the advance of spark timing could lead to a decreased time interval during the expansion phase, for which high temperature levels persist in the cylinder. The latter affects negatively the $\mathrm{CO}$ oxidation rate and so allows for less mass of the formed $\mathrm{CO}$ to be completely oxidized [30-32]. 
Finally, by examining Figure 9a,b, it is observed that for both loads examined and for constant ignition timing, the full replacement of gasoline either by butanol or by ethanol fuel leads to a slight decrease of the indicated specific CO concentrations. This may be attributed to the fact that for the same ignition timing, the engine operation under alcohol-fuel operating mode (B100 or E100) results in lower burning zone temperatures during the expansion phase, which affects negatively (restrain) the $\mathrm{CO}$ formation mechanism. Therefore, by taking into account the fact that under alcohol-fuel operating mode a slightly more indicated power output is calculated, the lower, relative to that of the G100 operating mode, values of the calculated indicated specific $\mathrm{CO}$ emissions observed under both the B100 or E100 operating modes are justifiable.

\section{Conclusions}

In the present work, an existing two-zone phenomenological model is used to examine the effect of spark timing on the performance and emissions of a light-duty, SI engine running under either gasoline or ethanol or butanol fuel operating modes. A good coincidence for both performance characteristics and pollutant emissions was observed between calculated and measured values, which correspond to the same engine operating point, i.e., $100 \%$ of full engine load and spark timing equal to 23 deg CA BTDC, either under gasoline-fuel operating mode or ethanol-fuel one.

By comparing computed and measured values, a very good coincidence is observed for brake power and bsfc for both fuel operating modes examined. In the case of indicated isfc, and indicated specific $\mathrm{NO}$ and $\mathrm{CO}$ emissions, also a satisfactory agreement between calculated and experimental values was observed. At full engine loading conditions, the developed simulation model seems to predict with reasonable accuracy the trend variation of main performance parameters and $\mathrm{NO}$ and $\mathrm{CO}$ emissions, when the engine is running under either gasoline or ethanol operating modes, respectively. Acknowledging the predictive ability of the model, this was used to examine the effects of the type of fuel and the spark advance, at both part and full engine loading points, on the cylinder pressure and heat release rate traces, indicated power output, maximum cylinder pressure, indicated specific fuel consumption, and specific $\mathrm{NO}$ and $\mathrm{CO}$ emissions. From the evaluation of the theoretical findings, the conclusions can be summarized as follows:

For each one of the three fuel-operating modes examined herein (G100, B100 and E100), the increase of engine loading conditions by keeping constant both the spark timing and fuel equivalence ratio, results in a slight deterioration (slight increase) of the indicated specific fuel consumption. But, at the same time, it affects negatively (considerable increase) the maximum cylinder pressure. However, the increase in engine loading conditions does not appear to have a significant effect on the indicated specific $\mathrm{NO}$ and $\mathrm{CO}$ concentrations.

Moreover, for each type of fuel at the same engine load, the advance of spark timing relative to normal start of ignition could lead to a slight increase of the indicated specific fuel consumption. On the other hand, a slight retard of the spark advance relative to normal spark timing, could lead to a slight improvement of the indicated engine efficiency (slight decrease of the isfc), which seems to become more sensible at high engine loading conditions. At the same time, the advance of the spark timing leads to a slight increase of the maximum cylinder pressure, a fact that does not seem to have detrimental repercussions on the constructional endurance of the engine, since the differences observed in the maximum cylinder pressures are so small that they could be considered negligible. As far as the effect of spark timing on the specific concentrations of both $\mathrm{NO}$ and $\mathrm{CO}$ emissions is concerned, it is revealed that the advance of the initiation of combustion initiation seems to affect negatively (increase of indicated specific $\mathrm{NO}$ and $\mathrm{CO}$ concentrations) the environmental behavior of the engine. This effect becomes more intense at high engine loading conditions.

Finally, regarding the effect of the type of fuel on engine performance characteristics, it is revealed that for both engine loading conditions examined, the engine operation at constant spark timing either under the B100 or under the E100 operating modes results in an increase, as compared to the one recorded under the G100 operating mode, of the indicated specific fuel consumption. At the same 
time, it does not seem to affect negatively (i.e., considerable increase) the maximum cylinder pressure. As far as the effect of the type of the fuel on the environmental behavior of the engine is concerned, it is shown that the full replacement of gasoline by an alcohol one appears to have a positive effect on the environmental behavior of the engine, since it results in a worthwhile decrease of the indicated specific concentrations of both $\mathrm{NO}$ and $\mathrm{CO}$ emissions. Moreover, by comparing the relative results between the B100 and the E100 operating modes, it is revealed that for each engine operating point (combination of engine load and spark timing), the use of ethanol instead of butanol may result in lower specific concentrations of both $\mathrm{NO}$ and $\mathrm{CO}$ emissions. This effect seems to become more sensible at higher engine loading conditions.

The results of this preliminary investigation are encouraging and urge us to conduct a more thorough, in relation to the present one, parametric study. Such a study is currently under progress and the first results of this will be given in the near future. Even though it is difficult to generalize the findings of the current preliminary investigation, we believe that they are important since the use of an alcohol (butanol or ethanol) instead of gasoline with retarded spark timing in a light-duty, SI engine, could be a promising solution for increasing the engine efficiency, while simultaneously improving the environmental behavior of the engine. The effect becomes more sensible at full load conditions. However, this potential may be limited by considering that at full load conditions the use of an alcohol (butanol or ethanol) instead of gasoline could result in an essential increase of the maximum cylinder pressure, which could be a crucial issue for the operational lifetime of an existing engine.

Author Contributions: Roussos G. Papagiannakis was involved with setting-up and running the simulation program, and comparing the results of analysis. Dimitrios C. Rakopoulos was involved with the evaluation and interpretation of the analysis results. Constantine D. Rakopoulos provided scientific guidance throughout the whole process and authored the paper.

Conflicts of Interest: The authors declare no conflict of interest.

\section{References}

1. Demain, A.L. Biosolutions to the energy problem. J. Ind. Microbiol. Biotechnol. 2009, 36, 319-332. [CrossRef] [PubMed]

2. Festel, G.W. Biofuels-Economic aspects. Chem. Eng. Technol. 2008, 31, 715-720. [CrossRef]

3. Wallner, T.; Miers, S.A.; McConnell, S. A comparison of ethanol and butanol as oxygenates using a direct-injection, spark-ignition engine. ASME J. Eng. Gas Turbines Power 2009, 131, 032802. [CrossRef]

4. Korakianitis, T.; Namasivayam, A.M.; Crookes, R.J. Natural-gas fuelled spark-ignition (SI) and compression-ignition (CI) engine performance and emissions. Prog. Energy Combust. Sci. 2011, 37, 89-112. [CrossRef]

5. Papagiannakis, R.G.; Rakopoulos, C.D.; Hountalas, D.T.; Giakoumis, E.G. Study of the performance and exhaust emissions of a spark-ignited engine operating on syngas fuel. Int. J. Altern. Propuls. 2007, 1, $190-215$. [CrossRef]

6. Rakopoulos, D.C.; Rakopoulos, C.D.; Giakoumis, E.G.; Dimaratos, A.M.; Kyritsis, D.C. Effects of butanol-diesel fuel blends on the performance and emissions of a high-speed DI diesel engine. Energy Convers. Manag. 2010, 51, 1989-1997. [CrossRef]

7. Rakopoulos, D.C.; Rakopoulos, C.D.; Papagiannakis, R.G.; Kyritsis, D.C. Combustion heat release analysis of ethanol or $n$-butanol diesel fuel blends in heavy-duty DI diesel engine. Fuel 2011, 90, 1855-1867. [CrossRef]

8. Rice, R.W.; Sanyal, A.K.; Eirod, A.C.; Bata, R.M. Exhaust gas emissions of butanol, ethanol, and methanol-gasoline blends. ASME J. Eng. Gas Turbines Power 1991, 113, 377-381. [CrossRef]

9. Costagliola, M.A.; De Simio, L.; Iannaccone, S.; Prati, M.V. Combustion efficiency and engine out emissions of a S.I. engine fueled with alcohol/gasoline blends. Appl. Energy 2013, 111, 1162-1171. [CrossRef]

10. Shenghua, L.; Clemente, R.C.; Tiegang, H.; Yanjv, W. Study of spark ignition engine fueled with methanol/gasoline fuel blends. Appl. Therm. Eng. 2007, 27, 1904-1910.

11. Mustafi, N.N.; Raine, R.R. Application of a spark ignition engine simulation tool for alternative fuels. ASME J. Eng. Gas Turbines Power 2008, 130, 012804. [CrossRef] 
12. Koç, M.; Sekmen, Y.; Topgu, T.; Yucesu, H.S. The effects of ethanol-Unleaded gasoline blends on engine performance and exhaust emissions in a spark-ignition engine. Renew. Energy 2009, 34, 2101-2106. [CrossRef]

13. Bayraktar, H. Experimental and theoretical investigation of using gasoline-ethanol blends in spark-ignition engines. Renew. Energy 2005, 30, 1733-1747. [CrossRef]

14. Balki, M.K.; Sayin, C. The effect of compression ratio on the performance, emissions and combustion of an SI (spark ignition) engine fueled with pure ethanol, methanol and unleaded gasoline. Energy 2014, 71, $194-201$. [CrossRef]

15. Schaefer, A.J.; Hardenberg, H.O. Ignition Improvers for Ethanol Fuels; SAE Technical Paper 810249; SAE International: New York, NY, USA, 1981.

16. Veloo, P.S.; Wang, Y.L.; Egolfopoulos, F.N.; Westbrook, C.K. A comparative experimental and computational study of methanol, ethanol, and n-butanol flames. Combust. Flame 2010, 157, 1989-2004. [CrossRef]

17. Wigg, B.R. A Study on the Emissions of Butanol Using a Spark Ignition Engine and Their Reduction Using Electrostatically Assisted Injection. Master's Thesis, University of Illinois at Urbana-Champaign, Urbana, IL, USA, 2011.

18. Feng, R.; Fu, J.; Yang, J.; Wang, Y.; Li, Y.; Deng, B.; Liu, J.; Zhang, D. Combustion and emissions study on motorcycle engine fueled with butanol-gasoline blend. Renew. Energy 2015, 81, 113-122. [CrossRef]

19. Tornatore, C.; Irimescu, A.; Marchitto, L.; Merola, S.S.; Valentino, G. Combustion process analysis in a DISI engine fuelled with n-butanol through UV-VIS emission spectroscopy. Int. J. Eng. Technol. 2015, 7, $242-248$. [CrossRef]

20. Szwaja, S.; Naber, J.D. Combustion of $n$-butanol in a spark-ignition IC engine. Fuel 2010, 89, 1573-1582. [CrossRef]

21. Tornatore, C.; Marchitto, L.; Mazzei, A.; Valentino, G.; Corcione, F.E.; Merola, S.S. Effect of butanol blend on in-cylinder combustion process. Part 1: Spark ignition engine. J. KONES Powertrain Transp. 2011, 18, 427-438.

22. Feng, R.; Yang, J.; Zhang, D.; Deng, B.; Fu, J.; Liu, J.; Liu, X. Experimental study on SI engine fuelled with butanol-gasoline blend and $\mathrm{H}_{2} \mathrm{O}$ addition. Energy Convers. Manag. 2013, 74, 192-200. [CrossRef]

23. Dhamodaran, G.; Esakkimuthu, G.S.; Pochareddy, Y.K.; Sivasubramanian, H. Investigation of $n$-butanol as fuel in a four-cylinder MPFI SI engine. Energy 2017, 125, 726-735. [CrossRef]

24. Elfasakhany, A. Experimental study on emissions and performance of an internal combustion engine fueled with gasoline and gasoline/n-butanol blends. Energy Convers. Manag. 2014, 88, 277-283. [CrossRef]

25. Li, Y.; Meng, L.; Nithyanandan, K.; Lee, T.H.; Lin, Y.; Lee, C.-f.F.; Liao, S. Combustion, performance and emissions characteristics of a spark-ignition engine fueled with isopropanol- $n$-butanol-ethanol and gasoline blends. Fuel 2016, 184, 864-872. [CrossRef]

26. Li, Y.; Gong, J.; Deng, Y.; Yuan, W.; Fu, J.; Zhang, B. Experimental comparative study on combustion, performance and emissions characteristics of methanol, ethanol and butanol in a spark ignition engine. Appl. Therm. Eng. 2017, 115, 53-63. [CrossRef]

27. Papagiannakis, R.G.; Zannis, T.C.; Rakopoulos, D.C.; Rakopoulos, C.D. Effects of boost pressure and spark timing on performance and exhaust emissions in a heavy-duty spark-ignited wood-gas engine. ASCE J. Energy Eng. 2015, 141, C4014013. [CrossRef]

28. Papagiannakis, R.G.; Zannis, T.C. Thermodynamic analysis of combustion and pollutants formation in a wood-gas spark-ignited heavy-duty engine. Int. J. Hydrog. Energy 2013, 38, 12446-12464. [CrossRef]

29. Papagiannakis, R.G.; Zannis, T.C. Effect of wood-gas composition on performance and exhaust emission characteristics of a large spark-ignition engine. ASCE J. Energy Eng. 2014, 140, A4013002. [CrossRef]

30. Heywood, J.B. Internal Combustion Engine Fundamentals; McGraw-Hill: New York, NY, USA, 1988.

31. Ferguson, C.R. Internal Combustion Engines-Applied Thermosciences; John Wiley: New York, NY, USA, 1986.

32. Benson, R.S.; Whitehouse, N.D. Internal Combustion Engines; Pergamon Press: Oxford, UK, 1979.

33. Blizard, N.C.; Keck, J.C. Experimental and Theoretical Investigation of Turbulent Burning Model for Internal Combustion Engines; SAE Technical Paper 740191; SAE International: New York, NY, USA, 1974.

34. Lucas, G.G.; James, E.H. Computer Simulation of a Spark Ignition Engine; SAE Technical Paper 730953; SAE International: New York, NY, USA, 1973.

35. Lavoie, G. Correlations of Combustion Data for a SI Engine Calculations_Laminar Flame Speed, Quench Distance and Global Reaction Rates; SAE Technical Paper 780229; SAE International: New York, NY, USA, 1978.

36. Annand, W.J.D. Geometry of spherical flame propagation in a disc-shaped combustion chamber. J. Mech. Eng. Sci. 1970, 12, 146-149. [CrossRef] 
37. Annand, W.J.D. Heat transfer in the cylinders of reciprocating internal combustion engines. Proc. Inst. Mech. Eng. 1963, 177, 973-990.

38. Vickland, C.W.; Strange, F.M.; Bell, R.A.; Starkman, E.S. A consideration of the high temperature thermodynamics of internal combustion engines. Trans. SAE 1962, 70, 785-793.

39. Lavoie, G.A.; Heywood, J.B.; Keck, J.C. Experimental and theoretical study of nitric oxide formation in internal combustion engines. Combust. Sci. Technol. 1970, 1, 313-326. [CrossRef]

40. Broustail, G.; Seers, P.; Halter, F.; Moréac, G.; Mounaim-Rousselle, C. Experimental determination of laminar burning velocity for butanol and ethanol iso-octane blends. Fuel 2011, 90, 1-6. [CrossRef]

41. Aleiferis, P.G.; Serras-Pereira, J.; Richardson, D. Characterisation of flame development with ethanol, butanol, iso-octane, gasoline and methane in a direct-injection spark-ignition engine. Fuel 2013, 109, 256-278. [CrossRef]

42. Li, Q.; Jin, W.; Huang, Z. Laminar flame characteristics of C1-C5 primary alcohol-isooctane blends at elevated temperature. Energies 2016, 9, 511-528. [CrossRef]

43. Khudhair, O.; Shahad, H.A.K. A review of laminar burning velocity and flame speed of gases and liquid fuels. Int. J. Curr. Eng. Technol. 2017, 7, 183-197.

(C) 2017 by the authors. Licensee MDPI, Basel, Switzerland. This article is an open access article distributed under the terms and conditions of the Creative Commons Attribution (CC BY) license (http:/ / creativecommons.org/licenses/by/4.0/). 